Check for updates

Cite this: RSC Adv., 2018, 8, 41172

Received 20th September 2018 Accepted 30th November 2018

DOI: 10.1039/c8ra07822j

rsc.li/rsc-advances

\section{Effects of potassium permanganate conditioning on dewatering and rheological behavior of pulping activated sludge: mechanism and feasibility $\dagger$}

\begin{abstract}
Xin Zhang, (DD abd Hui Cai, ${ }^{\text {abd }}{ }^{\text {Jun Shen }}{ }^{c}$ and Hui Zhang ${ }^{\text {*a }}$
The difficulties in sludge dewatering are associated with the high organic content, colloidal materials in sludge solids and the high hydrophilicity of extracellular polymeric substances (EPS). Based on the principle of advanced oxidation processes, waste pulping activated sludge was subjected to potassium permanganate $\left(\mathrm{KMnO}_{4}\right)$ oxidation pretreatment and then the influence and mechanism on sludge dewatering were comprehensively investigated in the present study. At lower $\mathrm{KMnO}_{4}$ dosage, changes of the physicochemical and rheological characteristics were that: (1) as the sludge disintegration degree increased, the total extractable EPS increased and then the bound water were released; (2) the rheological behavior showed that the yield stress and viscosity decreased while flowability increased and the positive thixotropic behavior weakened; (3) the particle size and microscopic structure were changed insignificantly. These changes resulted in damaging the gel-like environment and making the surface of sludge floc stripped but did not completely induce the floc breakage as a result of $\mathrm{KMnO}_{4}$ with lower redox potential. Thus, sludge dewaterability was improved with the optimum dosage of $16 \mathrm{~g} \mathrm{~kg}^{-1}$ dry solid. On the perspective of environmental safety, $\mathrm{KMnO}_{4}$ conditioning on sludge dewatering is feasible.
\end{abstract}

\section{Introduction}

Since 2009, China has exceeded America in paper and paperboard production and consumption and became the largest producer in the world, accounting for $25 \%$ of the global total. ${ }^{1}$ But the annual per capita consumption of paper and paperboard (75 kg) in China is much lower than in many developed countries (310.9 kg in Belgium, 285.3 kg in Slovenia, 250.4 kg in Germany, 235.6 kg in Austria, 218.6 kg in America, and $208.7 \mathrm{~kg}$ in Japan). ${ }^{2}$ Therefore, there is still great development potential for the paper industry in China. However, this has resulted in the greater environmental problems which limited the development of industry in turn.

The pulp and paper industry is considered to be one of the most polluting, and energy and water consuming industries in the world. ${ }^{3}$ A large amount of pulping activated sludge (PAS) is produced from the sewage treatment plants. The disposal of sewage sludge is one of the expensive sectors in a sewage

ajiangsu Provincial Key Lab of Pulp and Paper Science and Technology, Nanjing Forestry University, Nanjing 210037, China. E-mail: zhnjfu@163.com

${ }^{b}$ State Key Laboratory of Pulp and Paper Engineering, South China University of Technology, Guangzhou 510640, China

${ }^{c}$ Lee \& Man Co. Ltd, Changshu 215500, China

dJiangsu Co-Innovation Center for Efficient Processing and Utilization of Forest Resources, Nanjing Forestry University, Nanjing 210037, China

† Electronic supplementary information (ESI) available: Table S. See DOI: 10.1039/c8ra07822j treatment plant, accounting for up to $50 \%$ of the total operating costs of the plant. ${ }^{4}$ Because the water content of PAS is about $98 \%,{ }^{5-7}$ dewatering is the key step for further treatment and disposal in order to reduce the sludge volume and drying costs.

Extracellular polymeric substances (EPS) are the main organic matter of sludge flocs ${ }^{8}$ and have significant effects on sludge dewaterability. ${ }^{\mathbf{9}, 10}$ Proteins (PN) and polysaccharides (PS) are the major components of EPS with approximately $70-80 \%$ of the total, ${ }^{11}$ influencing the bound water content. ${ }^{12}$ In addition, EPS also contain nucleic acids, humic substances, lipids, etc. Previous researches showed that as much as $98 \%$ of the water was bound in the EPS. ${ }^{\mathbf{1 3 1 4}}$ The bound water interacts with sludge floc by the chemical bonds or capillary phenomena and requires much more energy to be removed. ${ }^{15}$ The removal of the bound water is key to reduce the sludge cake moisture rate.

The difficulties in sludge dewatering can be related to the high organic content and colloidal matters in it, the high compressibility of sludge cake, and the high hydrophilicity of EPS. ${ }^{16}$ In order to improve the sludge dewatering, it is a prerequisite to choose the proper sludge conditioning methods. Various methods of pretreatment are reported in the literature. There are usually three different ways: (1) to improve sludge settleability by coagulation or flocculation of sludge particles in the addition of polyelectrolytes, such as polyaluminium chloride, ${ }^{17}$ ferric chloride $^{18}$ and cationic polyacrylamide; ${ }^{19}$ (2) to improve sludge cake filterability by reducing the sludge solids compressibility in the addition of some high porous inert minerals such as fly ash, ${ }^{20}$ gypsum, ${ }^{21}$ wood chips 
and wheat dregs, ${ }^{22}$ rice husk; ${ }^{23}$ (3) to release the bound water from EPS by disintegration of sludge using techniques such as advanced oxidation processes (AOPs), anaerobic digestion, ${ }^{15}$ ultrasonic, ${ }^{24}$ electro-dewatering ${ }^{7}$ and enzyme ${ }^{25}$ treatment. Moreover, more researches has been undertaken to apply these pretreatments and mechanical dewatering device ${ }^{6}$ in a number of combinations, aiming at enhancing the dewaterability at a high level. ${ }^{26,27}$

The sludge dewaterability is assessed by the dewatering efficiency and moisture content reduction rate of sludge cake. In the mill, chemical coagulants and flocculants are usually applied as the conditioners to improve sludge dewaterability, but can't increase the moisture content reduction rate of sludge cake. ${ }^{28,29}$ That is to say, whether coagulants and flocculants are added or not, the sludge cake moisture content is the same at enough dewatering time. Based on the analysis, the objective of sludge deep dewatering is to reduce the bound water content and then increase the sludge cake moisture reduction rate. It can be realized by disrupting sludge floc or changing the surface properties of floc, and then increase the free water content of sludge. ${ }^{30}$ Therefore, sludge disintegration becomes a research focus. ${ }^{31}$

Utilizing in situ chemical oxidation reaction, AOPs disintegrate the sludge floc, reduce the bound water content and then realize deep dewatering. The major reagents employed in the literature include ozone $\left(\mathrm{O}_{3}\right),{ }^{24}$ Fenton reagents, ${ }^{32,33}$ ferrite, ${ }^{34}$ persulfate, ${ }^{35}$ permanganate, ${ }^{36}$ etc. Fenton reagents are frequently used for sludge dewatering, but have to be used at low $\mathrm{pH}$ values $(\mathrm{pH}<4)$ to avoid hydrolysis and precipitation of $\mathrm{Fe}^{3+}$, which will destroy the treatment equipment in a long time and is the biggest flaw for sludge dewatering. ${ }^{32,37}$ Persulfate is also used for sludge dewatering effectively with higher redox potential, but the oxidation processes need to be activated by initiators including metal salts and heat, ${ }^{35}$ and then increase the operating difficulties and costs. Other additions in the AOPs also have the demerit of the higher cost. Among them, potassium permanganate $\left(\mathrm{KMnO}_{4}\right)$ is a strong oxidant and has been used effectiveness over a wide $\mathrm{pH}$ range for water disinfection, toxic matter oxidation, inhibiting the growth of algae, ${ }^{38,39}$ convenient operation, comparative stability and relatively low cost. ${ }^{40}$ The redox reactions of $\mathrm{KMnO}_{4}$ in acidic and alkaline condition are shown in eqn (1) and (2). ${ }^{36}$

$$
\begin{gathered}
\mathrm{MnO}_{4}^{-}+8 \mathrm{H}^{+}+5 \mathrm{e}=\mathrm{Mn}^{2+}+4 \mathrm{H}_{2} \mathrm{O} E^{\varphi}=1.51 \mathrm{~V} \\
\mathrm{MnO}_{4}{ }^{-}+2 \mathrm{H}_{2} \mathrm{O}+3 \mathrm{e}=\mathrm{MnO}_{2}+4 \mathrm{OH}^{-} E^{\varphi}=0.59 \mathrm{~V}
\end{gathered}
$$

Most references are related to the municipal activated sludge for sludge dewatering; experimental studies that have actually used activated sludge from pulp and paper mills are rare. The characteristics are considerably different between PAS and municipal sludge, mainly because of the large amount of lignocellulosic material in the former. ${ }^{41}$ Take the example of municipal sludge, Wu et al. ${ }^{36}$ and $\mathrm{Wu}$ et $a .^{31}$ have preliminary studied the sludge disintegration using $\mathrm{KMnO}_{4}$ as the oxidant, but not systematically and with a higher dosage of the oxidant. Wu et al. ${ }^{36}$ investigated the relationship between the sludge disintegration degree (DD) and $\mathrm{KMnO}_{4}$ dosage; the DD reached a maximum of $34 \%$ with the dosage of about $100 \mathrm{~g} \mathrm{~kg}^{-1}$ dry solid (DS) and the particle size was almost unchanged within 3 minutes. And then, Wu et al. ${ }^{31}$ studied the relationship between the $\mathrm{KMnO}_{4}$ dosage and sludge dewaterability, and speculated that the poor of the dewaterability was caused by the decrease of sludge particle size, which is inconsistent with the former researcher's conclusion. Therefore, the mechanism of $\mathrm{KMnO}_{4}$ conditioning and how $\mathrm{KMnO}_{4}$ conditioning influencing the sludge dewatering still remain unclear. Additionally, whether $\mathrm{KMnO}_{4}$ treatment is feasible for the sludge dewatering needs to be analyzed from the perspective of environmental safety. Rheological properties of sludge play key roles in processes such as pumping, dewatering, drying and mixing, ${ }^{42}$ which are important macroscopic physical properties that reflect the change of the sludge microscopic structure. It is well known that sewage sludge is a non-Newtonian fluid, that exhibits rheological behavior, such as shear-thinning, thixotropy, yield stress and viscoelasticity. ${ }^{43-46}$ Many reports showed that some pretreatment methods such as acid, ${ }^{47}$ alkali, ${ }^{48}$ ultrasonic,${ }^{24}$ hydrothermal, ${ }^{24}$ composite salt ${ }^{49}$ can change the previous rheological characteristics that can be used to reveal the change of physicochemical properties and dewaterability. However, little is known about the effects of $\mathrm{KMnO}_{4}$ conditioning on sludge rheology and how this would affect sludge dewaterability. Investigation of rheological behavior will help to reveal the mechanism of $\mathrm{KMnO}_{4}$ conditioning on sludge dewatering.

The objectives of this study in the PAS were to investigate the role and mechanism of $\mathrm{KMnO}_{4}$ conditioning with a lower dosage that include sludge conditioning, physicochemical characteristics, rheological behavior and sludge dewaterability, and hopefully to find out the method to further improve the sludge dewatering. And then the feasibility of $\mathrm{KMnO}_{4}$ conditioning on sludge dewatering was analyzed on the perspective of environmental safety and we hope the results would provide the fundamental theory of sludge dewatering.

\section{Materials and methods}

\subsection{Materials}

The PAS was obtained from an integrated pulping and paper mill located in Jiangsu Province, China. The sludge samples ( $\mathrm{pH}$ $=6.96$ ) were kept in a plastic container filled with ice during transportation. The sludge was gently thickened to $10 \mathrm{~g} \mathrm{~L}^{-1}$ (DS of $1.25 \%$ ) by settling. To minimize the microbial activity, samples were stored at $4{ }^{\circ} \mathrm{C}$ and used for less than 5 days. ${ }^{50} \mathrm{All}$ the tests were performed in triplicate. $\mathrm{KMnO}_{4}$ was purchased from Nanjing Chemical Reagent Co. (Nanjing, China) and was of chemical pure grade, which was prepared by making the solution $\left(3 \mathrm{~g} \mathrm{~L}^{-1}\right)$ prior to use.

\subsection{Sludge conditioning and dewatering}

Different dosages of $\mathrm{KMnO}_{4}$ were added into $100 \mathrm{~mL}$ sludge and the conditioned sludge was agitated for $3 \mathrm{~min}$. The dewaterability was evaluated with the specific resistance to filtration (SRF), moisture content of sludge cake and the time to filter 
(TTF). The sludge SRF was measured based on the method of Wisniewski and Grasmick, ${ }^{51}$ and Qi Y. et al. ${ }^{52}$ The TTF was obtained using the method described by Lo et $a .^{53}$ and was defined as the time required for the filtration volume to increase up to half of the sludge sample volume. The moisture content of the filtered sludge cake was calculated according to the method of Wu et al. ${ }^{31}$ In this study, sludge was put into Buchner funnel at $0.03 \mathrm{MPa}$ for the sludge vacuum filtration. Deep dewatering of sludge cake obtained from filtration dewatering was carried out by tablet press at a pressure of $1.25 \mathrm{MPa}$ for $1 \mathrm{~min}$, and the sludge cake moisture content also was measured.

\subsection{EPS extraction and analysis}

A heat extraction method was used to extract the loosely bound EPS (LB-EPS) and the tightly bound EPS (TB-EPS). ${ }^{54}$ After centrifugation, the extraction supernatants were filtered with a $0.45 \mu \mathrm{m}$ membrane and collected as soluble EPS (S-EPS), LBEPS and TB-EPS. And then the three EPS components were analyzed for PN and PS, respectively. The PN content was analyzed by a UV spectrophotometer (TU-1900, PERSEE, China) following the modified Lowry method using bovine albumin (Sangon Biotech, China) as standard. ${ }^{55}$ The PS content was measured by the anthrone-sulfuric acid method with glucose as standard. ${ }^{8}$ The total EPS was the sum of PN and PS. ${ }^{\mathbf{3 6}}$

\subsection{Rheological behavior measurement}

Rheological tests were performed on a rotational rheometer (Thermo Scientific ${ }^{\mathrm{TM}}$ HAAKE $^{\mathrm{TM}}$ MARS $^{\mathrm{TM}}$, HAAKE, Germany) equipped with HAAKE Rheowin software. Measurements were conducted at $20{ }^{\circ} \mathrm{C}$. The sensor geometry used in this study was a $2^{\circ}$ cone and a flat stationary plate of $60 \mathrm{~mm}$ diameter. The similar rheometer and cone-plate geometry were used by many researchers. ${ }^{43,46,56-59}$ The rheological properties of sludge under the steady shear test were analyzed as follows: firstly, the sludge sample was pre-sheared for $10 \mathrm{~min}$ at a shear rate of $5 \mathrm{~s}^{-1}$ and then allowed to rest for $10 \mathrm{~min}$; secondly, the measurements were performed by linearly increasing the shear rate from $5 \mathrm{~s}^{-1}$ to $500 \mathrm{~s}^{-1}$ over $5 \mathrm{~min}$ with 300 points, holding at $500 \mathrm{~s}^{-1}$ for $30 \mathrm{~s}$ (up-curve); finally, the shear rate was linearly decreased from $500 \mathrm{~s}^{-1}$ to $5 \mathrm{~s}^{-1}$ over $5 \mathrm{~min}$ with 300 points (down-curve). For making a comparison, the three most commonly used rheological models, namely Power law (eqn (3)), Herschel-Bulkley (eqn (4)) and Bingham law (eqn (5)) were used to describe the rheological behavior of sludge.

$$
\begin{gathered}
\tau=k \dot{\gamma}^{n} \\
\tau=k \dot{\gamma}^{n}+\tau_{\mathrm{y}} \\
\tau=\eta \dot{\gamma}+\tau_{\mathrm{y}}
\end{gathered}
$$

where $\tau$ is the shear stress $(\mathrm{Pa}), \tau_{\mathrm{y}}$ is the yield stress $(\mathrm{Pa}), \dot{\gamma}$ is the shear rate $\left(\mathrm{s}^{-1}\right), k$ is the consistency index $\left(\mathrm{Pa} \mathrm{s}^{n}\right), \eta$ is the apparent viscosity $\left(\mathrm{Pa} \mathrm{s}^{n}\right)$. The $n$ is the flow behavior index and a decrease or increase of $n$ from 1 indicates that the nonNewtonian flow characteristics are strengthened, ${ }^{\mathbf{6 0}}$ which is equal to 1 for Newtonian fluids, higher than 1 for dilatant fluids and lower than 1 for pseudo-plastic fluids. ${ }^{61}$

\subsection{Other physicochemical properties analysis}

Sludge moisture content and TSS were measured following standard methods. ${ }^{62}$ The particle size distributions of the raw and conditioned sludge samples were measured by a laser classifier (Topsizer, OMEC Co., China). Microstructural characteristic was investigated by scanning electron microscopy (SEM) (Quanta 200, FEI, America).

Differential scanning calorimetry (DSC) (DSC214 Polyma, NETZSCH, Germany) was performed to measure the bound water in the sludge cake. ${ }^{\mathbf{4 8}, 63}$ The amount of free water in the sludge sample was quantified from the peaks of the crystallization/melting data from the DSC graphs. The sludge sample was vacuum filtered and then a weighted amount of sludge cake was added to the DSC. The temperature of the sludge cake was first cooled from $20{ }^{\circ} \mathrm{C}$ to $-20^{\circ} \mathrm{C}$ at a rate of 10 $\mathrm{K} \min ^{-1}$ and then increased to $20{ }^{\circ} \mathrm{C}$ at the same rate. The amount of free water in the sludge cake was calculated by dividing the heat absorbed by the water's latent heat of melting ice $\left(334 \mathrm{~mJ} \mathrm{mg}^{-1}\right) .{ }^{48}$ Therefore, the bound water content (mg $\mathrm{mg}^{-1} \mathrm{DS}$ ) was defined as the difference between the total water content (measured by drying the cake at $105{ }^{\circ} \mathrm{C}$ ) and the free water content measured by DSC. ${ }^{\mathbf{6 4 , 6 5}}$

\subsection{Statistical analysis}

In this study, correlation analysis and analysis of variance were performed using the software SPSS 22. Pearson's correlation $(R)$ is the measurement of the linear correlation between two variables. The correlations were considered statistically significant at a $95 \%$ confidence interval $(p<0.05)$.

\section{Results and discussion}

\subsection{The dewaterability of the PAS}

The effect of $\mathrm{KMnO}_{4}$ conditioning on the sludge dewaterability was studied by measuring the SRF, TTF and the moisture content of sludge cake, as shown in Fig. 1. The SRF, TTF and the moisture content of sludge cake of the raw sludge were $1.70 \times$

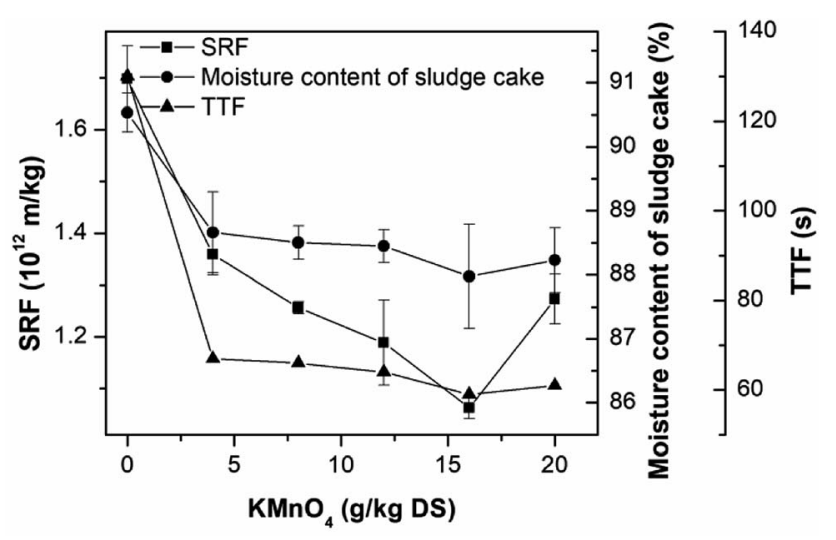

Fig. 1 Effect of $\mathrm{KMnO}_{4}$ dosage on sludge dewaterability. 
$10^{12} \mathrm{~m} \mathrm{~kg}^{-1}, 130 \mathrm{~s}$ and $90.53 \%$, respectively, showing poor dewaterability. An increase in the $\mathrm{KMnO}_{4}$ dosage from 0 to $16 \mathrm{~g}$ $\mathrm{kg}^{-1}$ DS significantly improved the sludge dewaterability, corresponding the reduction rates of $37.46 \%, 54.62 \%$ and $2.82 \%$ in the SRF, TTF and the moisture content, respectively. The sludge dewaterability became poor as the $\mathrm{KMnO}_{4}$ dosage was continued to add into the sludge sample. So the optimum $\mathrm{KMnO}_{4}$ dosage was $16 \mathrm{~g} \mathrm{~kg}^{-1}$ DS. This research was similar to the study of ultrasound pretreatment in the sludge dewatering. The lower intensities of ultrasound treatments improved sludge dewatering but the higher intensities were the opposite. ${ }^{66-68}$ Pearson's analysis showed that strong positively correlation were found between SRF and TTF $(R=0.922, p<0.01)$, SRF and moisture content $(R=0.957, p<0.01)$, and moisture content and TTF $(R=0.988, p<0.01)$. The three parameters can express the sludge dewaterability and filterability.

\subsection{The change of EPS contents in the PAS}

The total EPS content of the raw sludge was $30.38 \mathrm{mg} \mathrm{g}^{-1} \mathrm{DS}$. As shown in Fig. 2a, after the sludge conditioned with $\mathrm{KMnO}_{4}$, the total extractable EPS increased significantly with the percentage of $1 \%$ to $36.44 \%$; the content of S-EPS, LB-EPS and TB-EPS also increased with the increase of $\mathrm{KMnO}_{4}$ dosage, while the content of LB-EPS increased more quickly than that of other EPS components. For example, when the $\mathrm{KMnO}_{4}$ dosage was $20 \mathrm{~g}$ $\mathrm{kg}^{-1}$ DS, the content of S-EPS, LB-EPS and TB-EPS increased by $1.75 \%, 136.12 \%$ and $19.67 \%$, respectively. These results showed that the sludge DD increased and then lots of EPS were released from the sludge floc with $\mathrm{KMnO}_{4}$ oxidation, which were consistent with the research of Wu Y. et al. ${ }^{31}$ and Wu C. et al. ${ }^{36}$

The PN and PS of the raw sludge were 23.57 and $6.81 \mathrm{mg} \mathrm{g}^{-1}$ DS, respectively. Fig. 2b shows the effect of $\mathrm{KMnO}_{4}$ dosage on the variation of PN and PS within total EPS. With the increase of $\mathrm{KMnO}_{4}$ dosage, the contents of PN and PS increased with different changes. When the $\mathrm{KMnO}_{4}$ dosage was $20 \mathrm{~g} \mathrm{~kg}^{-1} \mathrm{DS}$, the PN increased by $35.05 \%$ and the PS increased by $38.21 \%$, compared with the raw sludge. The possible reason was that $\mathrm{KMnO}_{4}$ is likely to react with PN and PS in a different rate of degradation because of the different biochemical structure. ${ }^{69}$
The previous researches showed that the content of PN in the municipal sludge was more increased than that of PS, ${ }^{47,55}$ which were not consistent with our study. The reason was that the pulping sludge have much more PS such as cellulose and hemicellulose than other sludge. ${ }^{41}$

Fig. 2c expresses the contents of PN and PS in different fractions of EPS as sludge conditioned with $\mathrm{KMnO}_{4}$. With the increase of $\mathrm{KMnO}_{4}$ dosage, the contents of PS and PN in the LBEPS increased, the content of PN in the TB-EPS increased, the content of PN in the S-EPS decreased and the content of PS in the S-EPS remained almost unchanged while the content of PS in the TB-EPS decreased firstly and then increased. This was not consistent with the conclusion of Shi Y. et al. ${ }^{69}$ The reason was that the redox potential of $\mathrm{KMnO}_{4}\left(E^{\varphi}=0.59 \mathrm{~V}\right.$ for $\left.\mathrm{pH} \geq 7\right)$ is lower than that of persulfate $\left(E^{\varphi}=2.60 \mathrm{~V}\right)$ and the oxidation capacity of sludge floc was weaker. This resulted in less EPS released. In addition, a reaction balance of $\mathrm{KMnO}_{4}$ lied in between the oxidative degradation of released EPS and the oxidative rupture of floc surface.

\subsection{The rheological behavior in the PAS}

3.3.1. The general rheological behavior and parameters of the PAS. The steady shear flow in the range of 5-500 s $\mathrm{s}^{-1}$ was used to analyze the overall rheological behavior from low to high shear. As shown in Fig. 3, both the raw and $\mathrm{KMnO}_{4}$ conditioning sludge exhibited shear-thinning and pseudoplastic behavior.

The three rheological models were used to fit the shear stress and shear rate. The statistical coefficients are shown in Table 1. Compared to Power law model and Bingham plastic model, Herschel-Bulkley model was found to be more efficient to describe the rheological behavior of the raw and conditioned sludge with the highest coefficient. In the Herschel-Bulkley model, $\tau_{\mathrm{y}}, n$ and $k$ are comprehensively considered. $\tau_{\mathrm{y}}$ is the specified value of the stress exerted on sludge when it begins to flow. ${ }^{70}$ Lower $k$ value indicates sludge firmness is weak and trend of $k$ value is equal to the apparent viscosity. Based on the results of Herschel-Bulkley model, $\tau_{\mathrm{y}}$ values decreased, $k$ values decreased and $n$ values increased by $\mathrm{KMnO}_{4}$ conditioning. In
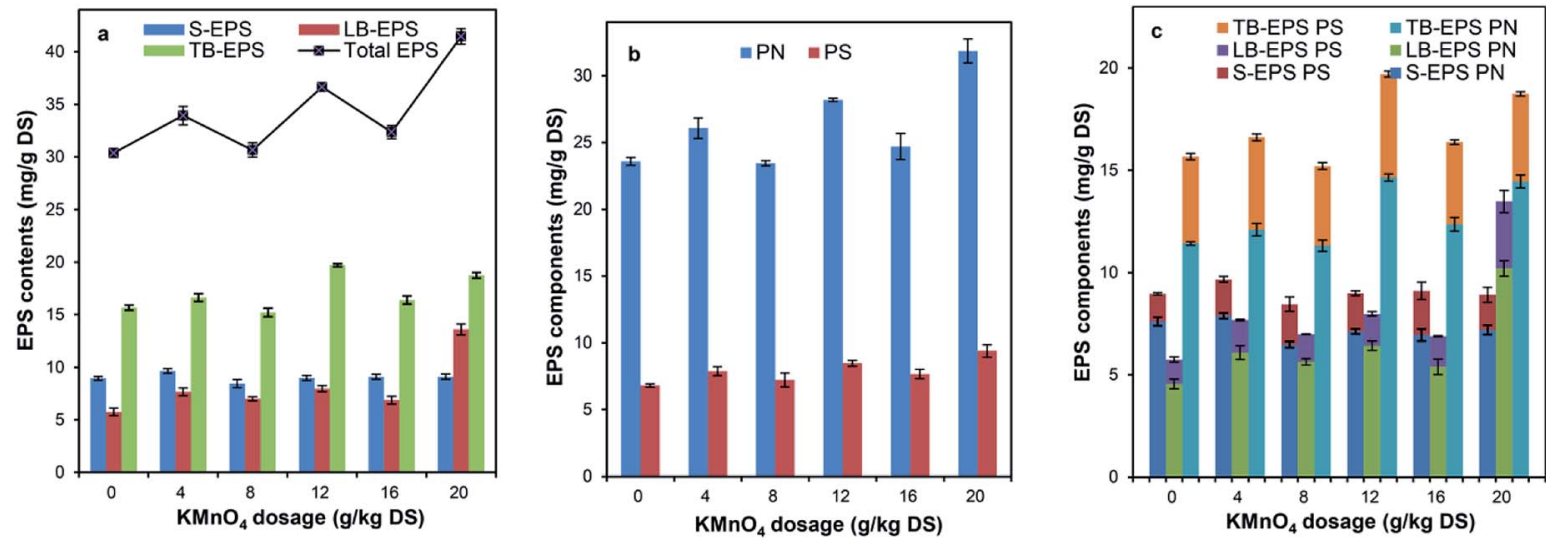

Fig. 2 The correlation of sludge between $\mathrm{KMnO}_{4}$ dosage and (a) quantities of EPS concentration (sum of PN and PS); (b) quantities of PN and PS in the total EPS; (c) PN and PS contents of the S-EPS, LB-EPS and TB-EPS. 


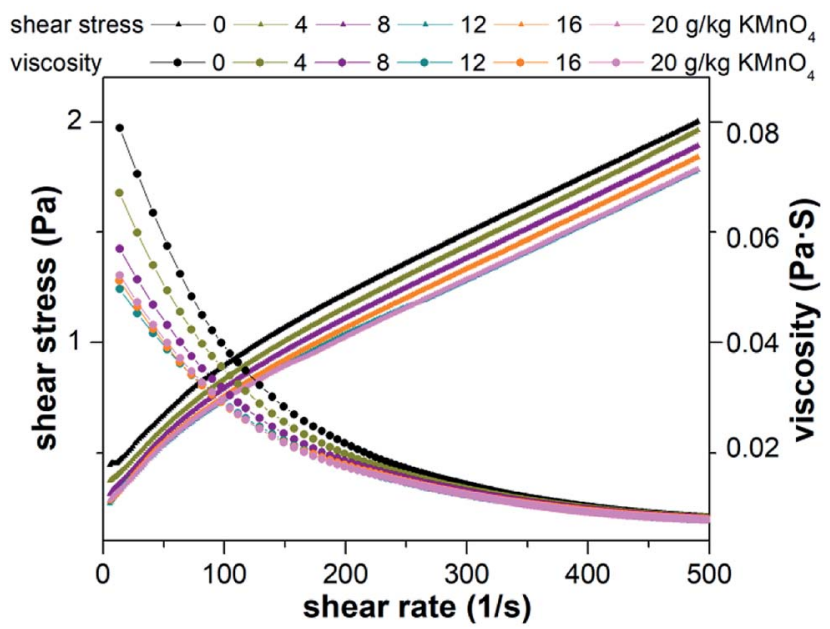

Fig. 3 Flow curves of raw sludge and $\mathrm{KMnO}_{4}$ conditioning sludge.

other words, sludge flowability increased and viscosity decreased, which agreed with the rheological results of Liu et al. ${ }^{71}$ and Wang et al. ${ }^{19}$ This phenomenon was the interaction between the sludge particles and was related to the weak steric hindrance in the sludge structure after pretreatment. This is consistent with the release of EPS, which can be an indication of the degree of sludge floc rupture. When the dosage of $\mathrm{KMnO}_{4}$ was $20 \mathrm{~g} \mathrm{~kg}^{-1} \mathrm{DS}$, it had a greater influence on sludge rheological behavior.

3.3.2. The thixotropic behavior of the PAS. Table 1 presents the steady state viscosity of the raw and conditioned sludge samples at a rate of $5 \mathrm{~s}^{-1}$. With the increase of $\mathrm{KMnO}_{4}$ dosage, the steady state viscosity was reduced from $78.701 \mathrm{mPa}$ s to $47.211 \mathrm{mPa}$ s with a reduction of $40 \%$. The sludge sample also exhibited thixotropic behavior, as observed by the presence of the hysteresis area (Fig. 4). The sludge showed positive thixotropic behavior, that is, shear stresses during the up-curves were higher than that during the down-curves at the same shear rate. As shown in Table 1 and Fig. $4, \mathrm{KMnO}_{4}$ pretreatment resulted in the decrease of the hysteresis area, as in the case of the steady state viscosity, the maximum reduction of $46.86 \%$ was observed at $20 \mathrm{~g} \mathrm{~kg}^{-1} \mathrm{DS}$, which indicated that the thixotropic behavior of sludge weakened. The thixotropic behavior of the sludge suggested that the kinetic processes of both breakdown and build-

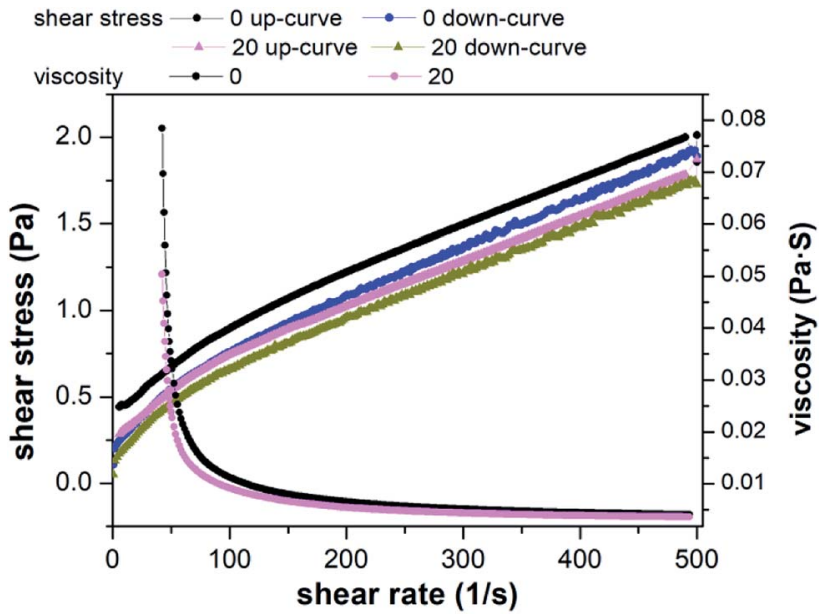

Fig. 4 Hysteresis loop as a function of shear rate at the raw sludge and $\mathrm{KMnO}_{4}$ conditioning sludge with $20 \mathrm{~g} \mathrm{~kg}^{-1} \mathrm{DS}$.

up exist when flow is applied. ${ }^{71}$ The hysteresis area became small, which indicated that the kinetic processes could rapidly reach a steady state. In general, activated sludge shows high levels of thixotropy due to its internal structures. ${ }^{72}$ The colloidal forces among particles tend to rebuild the structures. ${ }^{73}$ Therefore, the decrease of sludge thixotropy with $\mathrm{KMnO}_{4}$ conditioning may be caused by rupturing the sludge colloidal environment among particles.

\subsection{The bound water content and deep dewatering application of the PAS}

The DSC thermograms of the raw and conditioned sludge are shown in Fig. 5 . The area below the baseline was related to the free water content of the sludge sample. The bound water content during pretreatment can be obtained according to the free and total water content. The endothermic curve ranged from -2 to $15^{\circ} \mathrm{C}$, which was similar to that researched by Zhang $\mathrm{H}$. et $a l^{33}$ and was wider than that researched by RuizHernando M., ${ }^{48}$ possibly due to the difference of heating rates. The thermograms (Fig. 5a-f) were similar with each other but also had the slight differences, which was the result from the difference of sludge composition. ${ }^{63}$

Table 1 Fitting results of the models and rheological parameters at raw sludge and conditioned sludge with various $\mathrm{KMnO}_{4}$ dosages

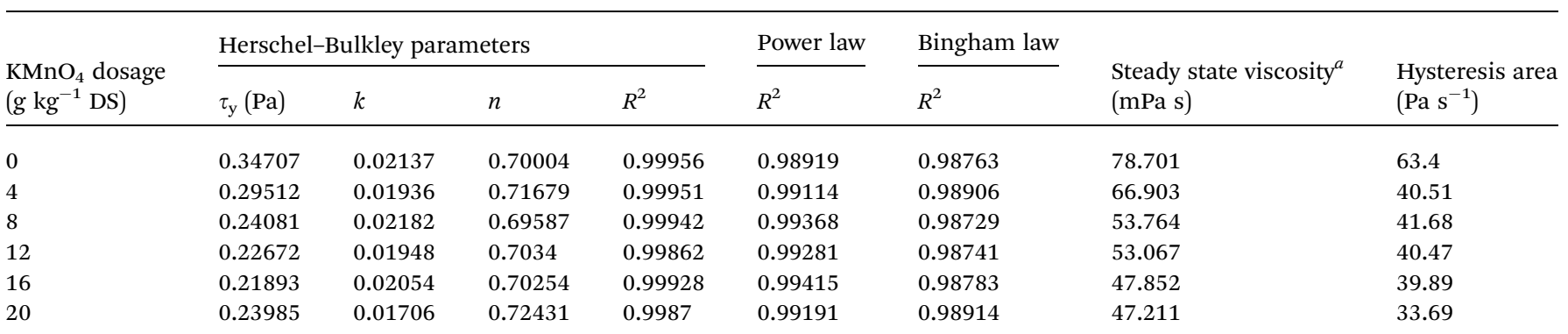

${ }^{a}$ Steady state viscosity of the raw and conditioned sludge samples at a rate of $5 \mathrm{~s}^{-1}$. 


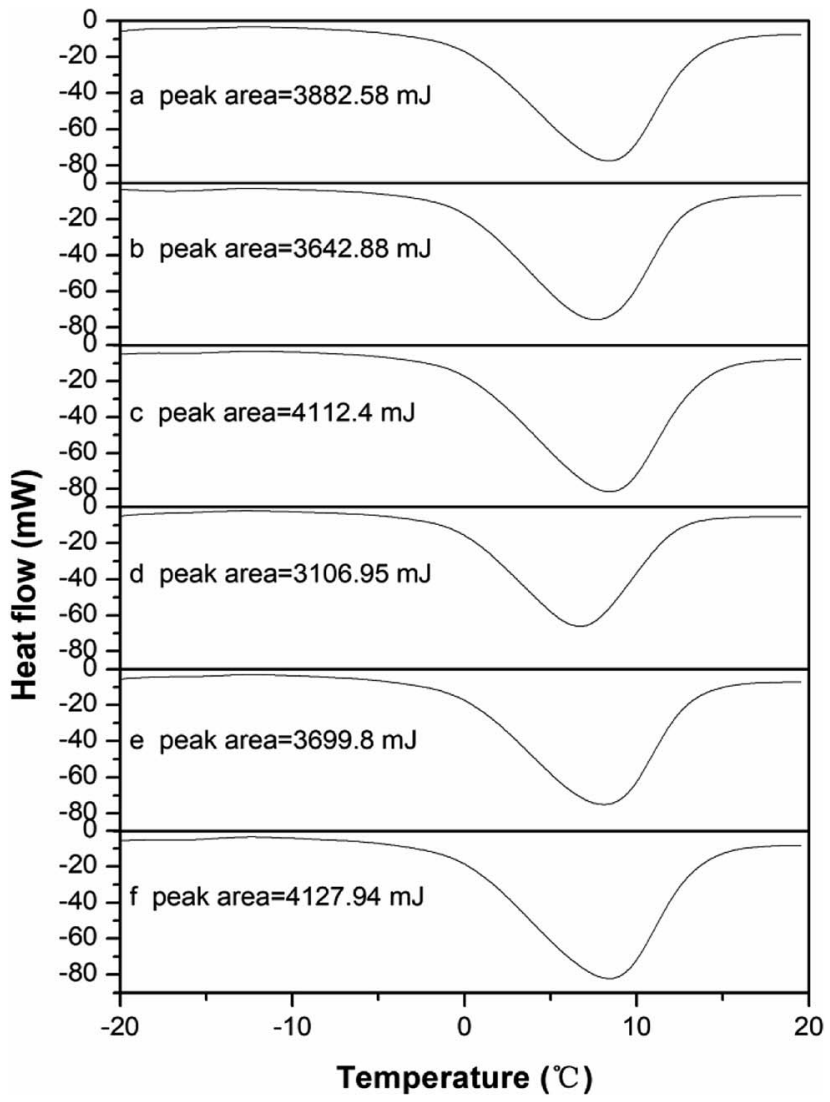

Fig. 5 DSC thermograms of the raw and conditioned sludge with different dosages of $\mathrm{KMnO}_{4}$ : (a) raw sludge, $13.7 \mathrm{mg}$; (b) conditioned sludge by $\mathrm{KMnO}_{4}$ with $4 \mathrm{~g} \mathrm{~kg}^{-1} \mathrm{DS}, 12.8 \mathrm{mg}$; (c) conditioned by $\mathrm{KMnO}_{4}$ with $8 \mathrm{~g} \mathrm{~kg}^{-1} \mathrm{DS}, 13.8 \mathrm{mg}$; (d) conditioned sludge by $\mathrm{KMnO}_{4}$ with $12 \mathrm{~g}$ $\mathrm{kg}^{-1} \mathrm{DS}, 10.5 \mathrm{mg}$; (e) conditioned sludge by $\mathrm{KMnO}_{4}$ with $16 \mathrm{~g} \mathrm{~kg}^{-1} \mathrm{DS}$, $13 \mathrm{mg}$; (f) conditioned sludge by $\mathrm{KMnO}_{4}$ with $20 \mathrm{~g} \mathrm{~kg}^{-1} \mathrm{DS}, 14.2 \mathrm{mg}$.

Fig. 6 shows the change of bound water content of the raw and conditioned sludge. As the $\mathrm{KMnO}_{4}$ dosage increased from 0 to $12 \mathrm{~g} \mathrm{~kg}^{-1} \mathrm{DS}$, the bound water content decreased from $1.58 \mathrm{~g} \mathrm{~g}^{-1}$ DS to $0.76 \mathrm{~g} \mathrm{~g}^{-1}$ DS significantly with the reduction of $51.68 \%$; when the $\mathrm{KMnO}_{4}$ dosage increased further to $20 \mathrm{~g} \mathrm{~kg}^{-1}$ DS, the bound water increased slightly to $0.97 \mathrm{~g} \mathrm{~g}^{-1} \mathrm{DS}$. The

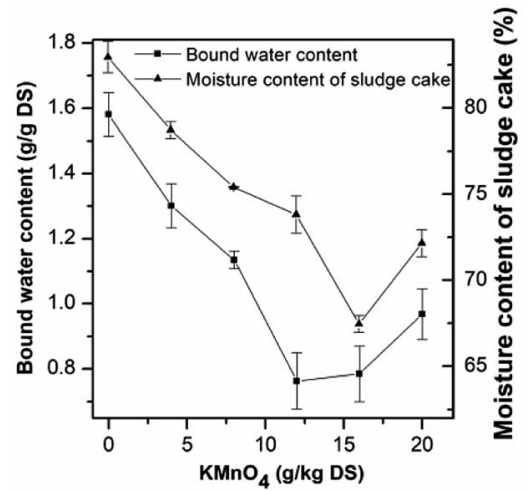

Fig. 6 Effect of $\mathrm{KMnO}_{4}$ dosage on the sludge bound water content and moisture content of sludge cake after deep dewatering. content of bound water was minimized nearly the $\mathrm{KMnO}_{4}$ dosage of $12 \mathrm{~g} \mathrm{~kg}^{-1} \mathrm{DS}$. The results indicated that the bound water was released and converted into free water as a result of EPS degraded after $\mathrm{KMnO}_{4}$ conditioning. The value of bound water in this research was different from other researches, ${ }^{33,47,48}$ which may be related to the non-uniformity of the sludge sample during DSC operating. Previous studies showed that the bound water was one of the major limiting factors influencing sludge dewatering efficiency and a decrease of the bound water was a key step to enhance the dewaterability. ${ }^{74}$ As $\mathrm{KMnO}_{4}$ was added into the sludge, the values of SRF and bound water decreased but had different reduction rates. This indicated that the bound water content can be related to not only SRF but also the combination with sludge particles. So it can express the sludge dewaterability on some extent.

As mentioned above, the moisture content of sludge cake was relatively high after dewatering at low pressure $(0.03 \mathrm{MPa})$ in the experiment of SRF. Therefore, high pressure (1.25 $\mathrm{MPa})$ was used to deep dewatering. As shown in Fig. 6, the moisture content of raw sludge decreased from $98.75 \%$ to $82.96 \%$, while that of the conditioned sludge with $16 \mathrm{~g} \mathrm{~kg}^{-1}$ DS decreased to $67.46 \%$ with the lowest value. The dewatered sludge cake with the lower moisture content could be beneficial for transportation and saving drying costs.

\subsection{The microstructural characteristic in the PAS}

The wet raw and conditioned sludge cake could be obtained by the SRF measurement. The former was relatively soft but the latter was compact. As shown in Fig. 7, there was no obvious change of particle size in the raw and conditioned sludge, which revealed that treatment did not cause complete floc rupture but stripped the floc surface by redox reaction. The change of particle size was similar to that in the sludge disintegration of $\mathrm{O}_{3}$ treatment. When the dosage was $0.1 \mathrm{~g} \mathrm{~g}^{-1} \mathrm{TS}^{-1}$, the median diameter decreased from $36.3 \mu \mathrm{m}$ for the raw sludge to 33.2 $\mu \mathrm{m} .{ }^{24}$ However, the particle size decreased significantly by ultrasound treatment, which broke aggregates, flocs and cells. ${ }^{75}$ Due to the creation of cation chemical bonds, some treatments such as thermal, ${ }^{24}$ acid $^{47}$ and potassium ferrite ${ }^{34}$ led to particles agglomeration and the particle size increased.

\subsection{The mechanism and feasibility of $\mathrm{KMnO}_{4}$ conditioning on the PAS dewatering}

In order to accurately analyze the relationship between the sludge dewaterability and other parameters and then elaborate the mechanism of $\mathrm{KMnO}_{4}$ conditioning on the sludge dewatering, Pearson's correlations were calculated (Table S†). The results showed that SRF was significantly positive correlated with the bound water content $(R=0.930, p<0.05)$, the steady state viscosity $(R=0.911, p<0.05)$, hysteresis area $(R=0.839, p$ $<0.05)$ and $\tau_{\mathrm{y}}(R=0.959, p<0.01)$; the significant positive correlations were also found between the bound water content and $\tau_{\mathrm{y}}(R=0.954, p<0.01)$, the bound water content and the steady state viscosity $(R=0.971, p<0.05)$, the steady state viscosity and $\tau_{\mathrm{y}}(R=0.971, p<0.01)$, and the steady state viscosity and hysteresis area $(R=0.865, p<0.05)$. Additionally, 

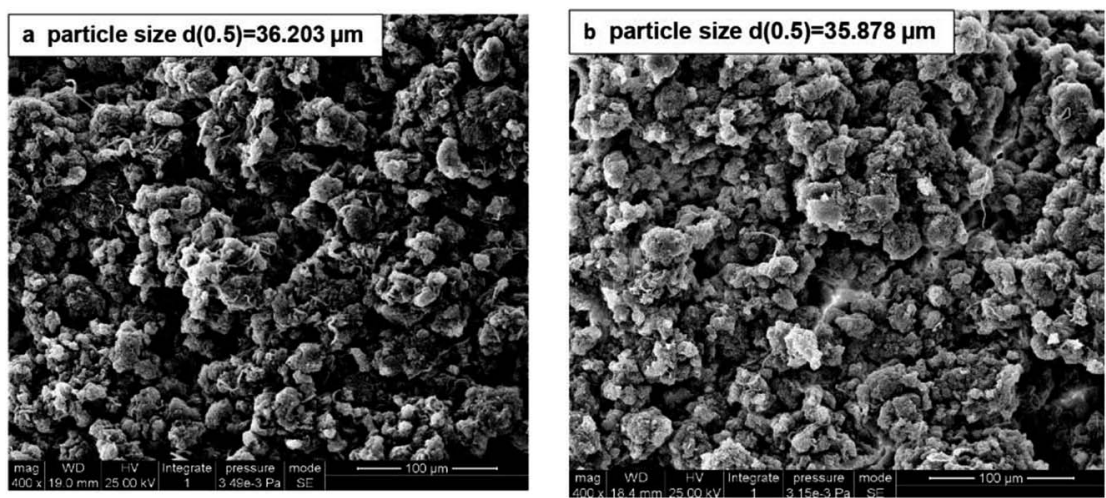

Fig. 7 SEM images of the raw sludge (a) and conditioned sludge cake with $\mathrm{KMnO}_{4}$ dosage of $16 \mathrm{~g} \mathrm{~kg}^{-1} \mathrm{DS}$ (b).

the $\mathrm{KMnO}_{4}$ dosage was significantly negative correlated with $\tau_{\mathrm{y}}$ $(R=0.837, p<0.05)$ and steady state viscosity $(R=0.928, p<$ 0.01). The content of the total EPS was significantly positive correlated with the content of LB-EPS $(R=0.933, p<0.01)$, the content of PN $(R=0.999, p<0.01)$, the content of PS $(R=0.987$, $p<0.01)$, the content of TB-EPS $(R=0.850, p<0.05)$ and $n(R=$ $0.814, p<0.05)$, but was significantly negative correlated with $k$ $(R=0.966, p<0.01)$. Moderate correlations were found between the other parameters. There are strong correlations between $\mathrm{KMnO}_{4}$ conditioning, the changes of the physiochemical and rheological characteristics, and sludge dewaterability, which can reflect the mechanism of sludge dewatering. Among them, the rheological behavior can indirectly reflect the sludge dewatering mechanism and act an indicator between conditioning and dewatering. The changes of EPS in different fractions can't directly reflect the change of sludge dewaterability clearly and the comprehensive analyses are needed. Additionally, in this study, the sludge dewaterability was poor with the $\mathrm{KMnO}_{4}$ dosage increasing continuously. We can speculate the reason that it is the comprehensive effect between the increase of EPS released and the decrease of free water content, and then resulted in the decrease of $\tau_{\mathrm{y}}$ and viscosity, which deny the speculation of Wu et al. ${ }^{31}$

Based on the experimental results, we can propose that the mechanism of $\mathrm{KMnO}_{4}$ conditioning on sludge dewatering includes three elements, that is, sludge conditioning, changes of the physicochemical and rheological characteristics and dewaterability, as shown in Fig. 8. These changes made the gellike environment damaged but did not completely induce the floc breakage as a result of the lower redox potential under the neutral $\mathrm{pH}$ value. Therefore, sludge dewaterability was improved. The enzyme ${ }^{25}$ and ozone ${ }^{24}$ has the weak dewaterability because of the low redox potential. Chen et al. $(2015)^{25}$ studied that the SRF decreased by about $25 \%$ after sludge conditioned with the optimum dosage of alpha amylase. Other oxidants with higher redox potential and flocculants are more effective on dewatering performance. ${ }^{18,34,35}$ Guo et al. $(2019)^{27}$ found that the SRF decreased by $36.4 \%$ when wheat straw powder was added alone, which was caused by the formation of skeleton channels in the sludge; the SRF decreased by $65.6 \%$ and deep dewatered sludge moisture content reached to $58.2 \%$ in the combination of wheat straw powder and persulfate, which was the result of strong oxidation and skeleton builder. And Shi et al. $(2015)^{21}$ studied the sludge dewatering effect conditioned with the individual or combination addition and found that the SRF decreased by $91.6 \%$ with the combination addition. In this study, the SRF decreased by $37.46 \%$ after the sludge conditioned with $\mathrm{KMnO}_{4}$, which was similar to that conditioned with weaker oxidants and skeleton builders. Therefore, the combination conditioning methods might be

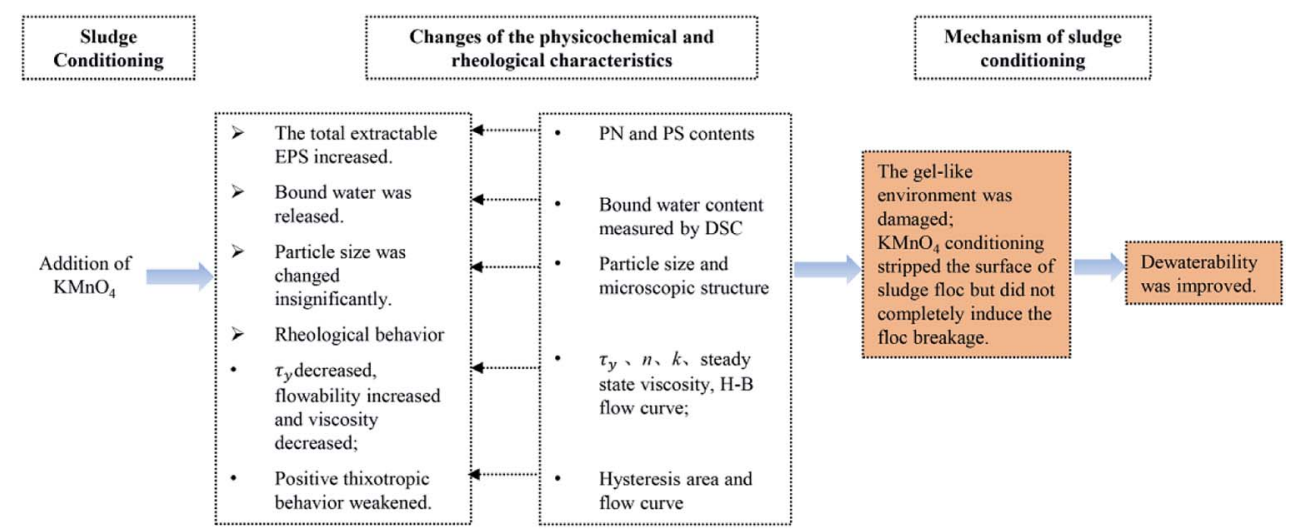

Fig. 8 The proposed mechanism of $\mathrm{KMnO} 4$ conditioning on pulping sludge dewatering. 
better for further improve the dewatering in the practice and will be the next research.

The value of $\mathrm{pH}$ in the pulping sludge is close to neutral $(\mathrm{pH}$ $=6.96$ ) and after $\mathrm{KMnO}_{4}$ oxidation, the $\mathrm{Mn}$ state in the filtrate mainly transferred to $\mathrm{Mn}^{2+}$ and $\mathrm{MnO}_{4}^{-}$. According to the national standard (GB 18918-2002), ${ }^{76}$ the maximum limit of the gross $\mathrm{Mn}$ is $2 \mathrm{mg} \mathrm{L}{ }^{-1}$. After $\mathrm{KMnO}_{4}$ pretreatment, the $\mathrm{Mn}$ content in the filtrate is very low (only $4 \mathrm{mg} \mathrm{L}^{-1}$ for $\mathrm{KMnO}_{4}$ dosage with $100 \mathrm{~g} \mathrm{~kg}^{-1}$ DS). ${ }^{36}$ Considering the smaller percentage of sludge in the wastewater $(1-2 \%),{ }^{77} \mathrm{KMnO}_{4}$ pretreatment will not cause the Mn content exceeding the national standard and conform to the local environment policy. Most of the Mn are deposited in the sludge cake in the form of $\mathrm{MnO}_{2}$, which is relatively stable, nontoxic and may insignificantly influence the further sludge treatment and disposal. Therefore, it is feasible for sludge conditioning with $\mathrm{KMnO}_{4}$ oxidation.

\section{Conclusions}

This study investigated the effect and mechanism of $\mathrm{KMnO}_{4}$ conditioning on sludge dewaterability by changes of the physicochemical and rheological characteristics. After the sludge conditioned with a lower dosage of $\mathrm{KMnO}_{4}$, the main changes were as follows.

(1) The sludge dewaterability was significantly improved and the optimum dosage was $16 \mathrm{~g} \mathrm{~kg}^{-1} \mathrm{DS}$, corresponding the reduction rate of SRF, moisture content and TTF by $37.46 \%$, $2.82 \%$ and $54.62 \%$.

(2) The total extractable EPS increased significantly, while the content of LB-EPS increased more quickly than that of other EPS components.

(3) The sludge flowability increased, viscosity decreased and the sludge thixotropic behavior became weakened, which may be the reason of rupturing the sludge colloidal environment among particles.

(4) The bound water was released and converted into free water as a result of EPS degraded and deep dewatered sludge moisture content reached to $67.46 \%$ under 1.25 MPa pressure.

(5) There was no obvious change of particle size in the raw and conditioned sludge.

Then the mechanism of $\mathrm{KMnO}_{4}$ conditioning on sludge dewatering was systematically elaborated. The pretreatment made the gel-like environment damaged but did not completely induce the floc breakage as a result of the lower redox potential under the neutral $\mathrm{pH}$ value. Therefore, sludge dewaterability was improved. On the perspective of environmental safety, it is feasible for $\mathrm{KMnO}_{4}$ conditioning on sludge dewatering.

\section{Conflicts of interest}

There are no conflicts to declare.

\section{Acknowledgements}

This research was supported by grants from the Open Foundation of State Key Lab of Pulp and Paper Engineering at South
China University of Technology (201780), National Major Science and Technology Program for Water Pollution Control and Treatment (2017ZX07402004) and the Priority Academic Program Development of Jiangsu Higher Education Institution (PAPD).

\section{References}

1 B. Q. Lin and Q. Y. Zheng, J. Cleaner Prod., 2017, 140, 11051117.

2 C. Guo and S. Kuang, China Paper Newsletters, 2018, 64-68.

3 D. Pokhrel and T. Viraraghavan, World Pulp \& Paper, 2005, 333, 37-58.

4 L. Appels, J. Baeyens, J. Degrève and R. Dewil, Prog. Energy Combust. Sci., 2008, 34, 755-781.

5 A. Elliott and T. Mahmood, Water Res., 2007, 41, 4273-4286. 6 A. MahmoudEmail, J. Olivier, J. Vaxelaire and A. F. A. Hoadley, Advances in Mechanical Dewatering of Wastewater Sludge Treatment, Springer, Netherlands, 2013.

7 A. Mahmoud, J. Olivier, J. Vaxelaire and A. F. A. Hoadley, Water Res., 2010, 44, 2381-2407.

8 F. Frølund, R. Palmgren, K. Keiding and P. H. Nielsen, Water Res., 1996, 30, 1749-1758.

9 J. Zhou, G. Zheng, X. Zhang and L. Zhou, PLoS One, 2014, 9, e102688.

10 X. Y. Li and S. F. Yang, Water Res., 2007, 41, 1022-1030.

11 L. Shao, P. He, G. Yu and P. He, J. Environ. Sci., 2009, 21, 8388.

12 L. Zheng, S. Y. Sun, Y. B. Xu, B. J. Liu, W. T. Yao, M. S. Cai and W. J. Tong, Adv. Mater. Res., 2011, 347-353, 2008-2014.

13 H. Liu and H. Fang, J. Biotechnol., 2002, 95, 249-256.

14 B. Jin, B. Wilén and P. Lant, Chem. Eng. J., 2004, 98, 115-126.

15 K. Song, X. Zhou, Y. Liu, G. Xie, D. Wang, T. Zhang, C. Liu, P. Liu, B. Zhou and Q. Wang, Chem. Eng. J., 2016, 295, 436-442.

16 D. Mowla, H. N. Tran and D. G. Allen, Biomass Bioenergy, 2013, 58, 365-378.

17 B. Peeters, R. Dewil, L. Vernimmen, B. Van den Bogaert and I. Y. Smets, Water Res., 2013, 47, 3600-3609.

18 M. Niu, W. Zhang, D. Wang, Y. Chen and R. Chen, Bioresour. Technol., 2013, 144, 337-343.

19 H. Wang, H. Wang, H. Hu and R. J. Zeng, RSC Adv., 2017, 7, 30274-30282.

20 C. Chen, P. Zhang, G. Zeng, J. Deng and Y. Zhou, Chem. Eng. J., 2010, 158, 616-622.

21 Y. Shi, J. Yang, W. Yu, S. Zhang, S. Liang, J. Song, Q. Xu, N. Ye, S. He and C. Yang, Chem. Eng. J., 2015, 270, 572-581.

22 Y. Lin, S. Jing and D. Lee, Bioresour. Technol., 2001, 76, 161163.

23 Y. Wu, P. Zhang, H. Zhang, G. Zeng, J. Liu, J. Ye, W. Fang and X. Gou, Bioresour. Technol., 2016, 205, 258-263.

24 C. Bougrier, C. Albasi, J. P. Delgenès and H. Carrère, Chem. Eng. Process., 2006, 45, 711-718.

25 Z. Chen, W. Zhang, D. Wang, T. Ma and R. Bai, Water Res., 2015, 83, 367-376.

26 C. Zhu, F. Li, P. Zhang, J. Ye, P. Lu and H. Wang, Powder Technol., 2018, 336, 191-198. 
27 S. Guo, H. Liang, L. Bai, F. Qu, A. Ding, B. Ji, X. Wang and G. Li, Chemosphere, 2018, 215, 333-341.

28 J. Novak, M. Agerbæk, B. Sørensen and J. Hansen, J. Environ. Eng., 1998, 125, 816-824.

29 J. Kopp and N. Dichtl, Water Sci. Technol., 2001, 43, 135-143. 30 J. Fu and W. Cai, J. Chem. Eng. Jpn., 2007, 40, 1113-1120.

31 Y. Wu, P. Zhang, G. Zeng, J. Liu, J. Ye, H. Zhang, W. Fang, Y. Li and Y. Fang, J. Taiwan Inst. Chem. Eng., 2017, 74, 121-128.

32 E. Neyens and J. Baeyens, J. Hazard. Mater., 2003, 98, 33-50.

33 H. Zhang, J. Yang, W. Yu, S. Luo, L. Peng, X. Shen, Y. Shi, S. Zhang, J. Song, N. Ye, Y. Li, C. Yang and S. Liang, Water Res., 2014, 59, 239-247.

34 C. Wu, L. Y. Jin, P. Y. Zhang, G. M. Zhang and R. Boopathy, Int. Biodeterior. Biodegrad., 2015, 102, 137-142.

35 G. Zhen, X. Lu, Y. Zhao, X. Chai and D. Niu, Bioresour. Technol., 2012, 116, 259-265.

36 C. Wu, G. Zhang, P. Zhang and C. Chang, Chem. Eng. J., 2014, 240, 420-425.

37 M. I. Badawy and M. E. Ali, J. Hazard. Mater., 2006, 136, 961966.

38 N. Li, M. Fan, J. Van Leeuwen, B. Saha, H. Yang and C. P. Huang, J. Environ. Sci., 2007, 19, 783-786.

39 J. Du, S. Bo, Z. Jing and G. Xiaohong, Environ. Sci. Technol., 2012, 46, 8860-8867.

40 J. Liang, X. Ning, X. Lai, H. Zou, J. Sun, X. Lu, Y. Zhang and T. An, J. Cleaner Prod., 2017, 151, 172-178.

41 T. Meyer and E. A. Edwards, Water Res., 2014, 321-349.

42 M. F. Xia, Z. W. Wang, Z. C. Wu, X. H. Wang and Z. Zhou, J. Environ. Sci., 2009, 21, 1639-1645.

43 N. Ratkovich, W. Horn, F. P. Helmus, S. Rosenberger, W. Naessens, I. Nopens and T. R. Bentzen, Water Res., 2013, 47, 463-482.

44 F. Markis, Sludge rheology: semi - empirical correlations to predict the apparent viscosity and yield stress of sludge mixtures, RMIT University, 2015.

45 J. Zhang, Y. Xue, N. Eshtiaghi, X. Dai, W. Tao and Z. Li, Water Res., 2017, 116, 34-43.

46 F. Yang, A. Bick, S. Shandalov, A. Brenner and G. Oron, J. Membr. Sci., 2009, 334, 83-90.

47 H. Wang, Y. Ma, H. Wang, H. Hu, H. Yang and R. J. Zeng, Water Res., 2017, 122, 398-406.

48 M. Ruiz-Hernando, F. Simón, J. Labanda and J. Llorens, Chem. Eng. J., 2014, 255, 14-22.

49 K. Xiao, Y. Chen, X. Jiang, Q. Yang, W. Y. Seow, W. Zhu and Y. Zhou, Water Res., 2017, 109, 13-23.

50 J. Conrardy, J. Vaxelaire and J. Olivier, Water Res., 2016, 100, 194-200.

51 C. Wisniewski and A. Grasmick, Colloids Surf., A, 1998, 138, 403-411.
52 Y. Qi, K. B. Thapa and A. F. A. Hoadley, Chem. Eng. J., 2011, 171, 373-384.

53 I. Lo, K. Lai and G. H. Chen, Environ. Sci. Technol., 2001, 35, 4691-4696.

54 G. Zhen, X. Lu, Y. Li, Y. Zhao, B. Wang, Y. Song, X. Chai, D. Niu and X. Cao, Bioresour. Technol., 2012, 119, 7-14.

55 B. Frølund, T. Griebe and P. H. Nielsen, Appl. Microbiol. Biotechnol., 1995, 43, 755-761.

56 L. Hammadi, A. Ponton and M. Belhadri, Energy Procedia, 2011, 6, 302-309.

57 B. Chen, S. Lee and D. J. Lee, Water Res., 2005, 39, 4429-4435.

58 R. Vankaam, D. Annearchard, M. Gaubert and C. Albasi, J. Membr. Sci., 2008, 317, 26-33.

59 F. Pignon, G. Belina, T. Narayanan, X. Paubel, A. Magnin and G. Gesan-Guiziou, J. Chem. Phys., 2004, 121, 8138-8146.

60 G. H. Feng, L. Y. Liu and W. Tan, Ind. Eng. Chem. Res., 2014, 27, 11185-11192.

61 X. Feng, B. Tang, L. Bin, H. Song, S. Huang, F. Fu, J. Ding, C. Chen and C. Yu, Biochem. Eng. J., 2016, 114, 147-154.

62 APHA, Standard Methods for the Examination of Water and Wastewater, American Public Health Association, Washington D.C., US, 21st edn, 2005.

63 D. Lee and S. F. Lee, J. Chem. Technol. Biotechnol., 1995, 62, 359-365.

64 N. Katsiris and A. Kouzeli-Katsiri, Water Res., 1987, 21, 13191327.

65 C. C. Wu, C. Huang and D. J. Lee, Water Res., 1998, 32, 900904.

66 F. Wang, M. Ji and S. Lu, Environ. Prog., 2006, 25, 257-260.

67 F. Hogan, S. Mormede, P. Clark and M. Crane, Water Sci. Technol., 2004, 50, 25-32.

68 J. Bien and L. Wolny, Water Sci. Technol., 1997, 36, 101-106.

69 Y. Shi, J. Yang, W. Mao, Y. Li, X. Xu, H. Zhang, W. Yu, Y. Li and C. Yang, Desalin. Water Treat., 2015, 53, 2655-2663.

70 S. Baroutian, N. Eshtiaghi and D. J. Gapes, Bioresour. Technol., 2013, 140, 227-233.

71 J. Liu, D. Yu, J. Zhang, M. Yang, Y. Wang, Y. Wei and J. Tong, Water Res., 2016, 98, 98-108.

72 J. Liu, Y. Wei, K. Li, J. Tong, Y. Wang and R. Jia, Water Res., 2016, 90, 225-234.

73 N. Eshtiaghi, F. Markis, S. D. Yap, J. C. Baudez and P. Slatter, Water Res., 2013, 47, 5493-5510.

74 J. Robinson and W. R. Knocke, Water Environ. Res., 1992, 64, 60-68.

75 A. Tiehm, K. Nickel, M. Zellhorn and U. Neis, Water Res., 2001, 35, 2003-2009.

76 GB 18918-2002, Discharge standard of pollutants for municipal wastewater treatment plant, Beijing, China, Ministry of Ecology and Environment of China, 2002.

77 G. Zhen, X. Lu, H. Kato, Y. Zhao and Y. Li, Renewable Sustainable Energy Rev., 2017, 69, 559-577. 